\title{
Apresentação atípica de infecção por herpes simples em um paciente imunossuprimido
}

\section{Atypical presentation of herpes simplex infection in a immunosupressed patient}

Maira Mitsue Mukai'; Isabelle de França Giostri²; Marina Serrato Coelho²; José Fillus Neto ${ }^{3}$; Sandra Moritz ${ }^{4}$

\section{unitermos}

Herpes simples virus

Apresentação atípica

Leucemia linfóide crônica

Imunossupressão

\section{resumo}

A infecção pelo vírus do herpes simples leva a um quadro clínico peculiar de fácil reconhecimento pelo médico. No entanto, em indivíduos imunossuprimidos, a apresentação clínica pode ser atípica, dificultando o diagnóstico e o tratamento. Em virtude disso, apresenta-se um caso de herpes simples ocorrendo em paciente submetido à quimioterapia.
The herpes simplex infection can produce peculiar clinical features easily recognized by the physician. However, in immunocompromised people, the clinical presentation can be atypical, difficulting the diagnosis and treatment. Therefore, a case of herpes simplex occurring in a pacient taking chemotherapy is presented.

\section{key words}

Herpes simplex virus

Atypical presentation

Chronic lymphoid leukemia

Immunossupression

\section{Introdução}

Em indivíduos imunocompetentes, as infecções pelo herpes vírus simples (HSV) apresentam-se tipicamente como placa eritematosa, seguida rapidamente pelo desenvolvimento de vesículas que, de modo eventual, coalescem e tornam-se crostas, raramente ulcerando ${ }^{(9)}$. Entretanto, nos imunossuprimidos, um defeito na imunidade mediada por células leva ao declínio da resposta imunológica ao HSV, podendo acarretar uma apresentação clínica atípica dessa condição cutânea comum ${ }^{(19)}$. Com o avanço da imunossupressão, as infecções pelo HSV podem se tornar crônicas e progressivas.

\section{Caso clínico}

Paciente do sexo masculino, 53 anos, lavrador, natural de Paranaguá e procedente de Pontal do Paraná. Em outubro de 2003 teve diagnóstico de leucemia linfóide crônica no estágio $C$ de Binnet, em consulta na hematologia. Submeteu-se a tratamento quimioterápico que incluiu clorambucil, fludarabina e ciclofosfamida, com término em março de 2003.

Dois meses após o final da quimioterapia surgiram placas eritematosas que evoluíram para lesões ulceradas na asa e na ponta do nariz, com acometimento da mucosa, acompanhadas de dor e prurido local.

1. Especializanda do Serviço de Dermatologia do Hospital de Clínicas de Curitiba da Universidade Federal do Paraná (UFPR).

2. Aluna do curso de Medicina da UFPR

3. Serviço de Anatomia Patológica do Hospital de Clínicas de Curitiba da UFPR.

4. Médica dermatologista do Serviço de Dermatologia do Hospital de Clínicas de Curitiba da UFPR.

Trabalho apresentado na categoria pôster na XIII Jornada Sul-Brasileira de Dermatologia, em Foz do Iguaçu (PR), 2004 
Foi encaminhado para avaliação dermatológica cerca de quatro meses após o início das lesões da pele. Ao exame havia úlceras rasas na asa nasal direita e na ponta do nariz, com aproximadamente dois centímetros de diâmetro (Figura 1).

Solicitou-se cultura das lesões ulceradas, havendo crescimento de Staphylococcus aureus, Streptococcus viridans e Streptococcus pneumoniae em moderada quantidade, possivelmente em função da contaminação da amostra. A pesquisa para fungos e bacilos álcool-ácido-resistentes foi negativa.

O estudo anátomo-patológico de biópsia da úlcera demonstrou a presença de crosta fibrinoleucocitária, restos celulares, acantose discreta com células com núcleos irregulares, com cromatina de aspecto lavado, algumas células multinucleadas com amoldamento nuclear presentes nas dermes superficial e média, extenso infiltrado inflamatório misto e ausência de granulomas (Figuras 2 e 3). Os achados histológicos foram sugestivos de infecção por vírus da família herpes.

Foi iniciado tratamento com aciclovir $200 \mathrm{mg}$ cinco vezes ao dia via oral, por dez dias. Houve melhora e resolução completa das lesões de pele após um mês.

\section{Discussão}

$O$ vírus do herpes simples, Herpesvirus hominis, determina quadros variáveis benignos ou graves ${ }^{(12)}$. São DNA vírus que causam infecção aguda da pele, caracterizada por vesículas agrupadas sobre uma base eritematosa. Raramente essas viroses vão provocar uma doença mais séria, porém a maioria das infecções é recorrente e tende a reaparecer

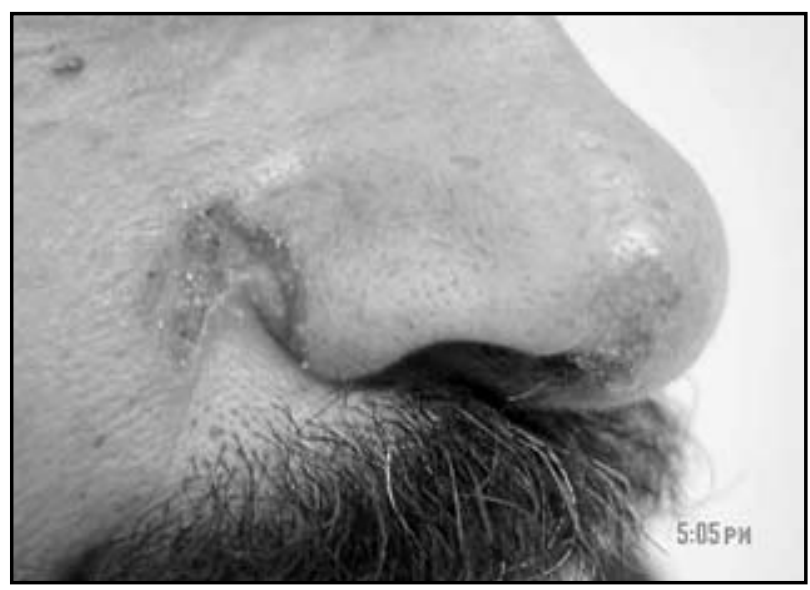

Figura 1 - Lesão ulcerada na asa nasal direita, com aspecto crostoso, medindo aproximadamente $2 \mathrm{~cm}$ de diâmetro, e outra lesão ulcerada na ponta do nariz, estendendo-se até a mucosa nasal

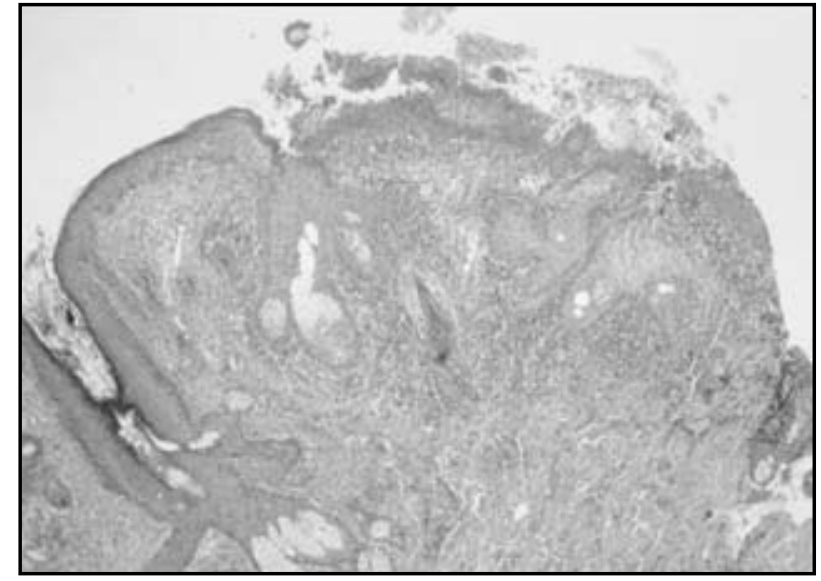

Figura 2 - Biópsia de pele de lesão ulcerada em região malar direita, com acantose discreta e infiltrado inflamatório misto nas dermes superficial e média (H\&E 40X)

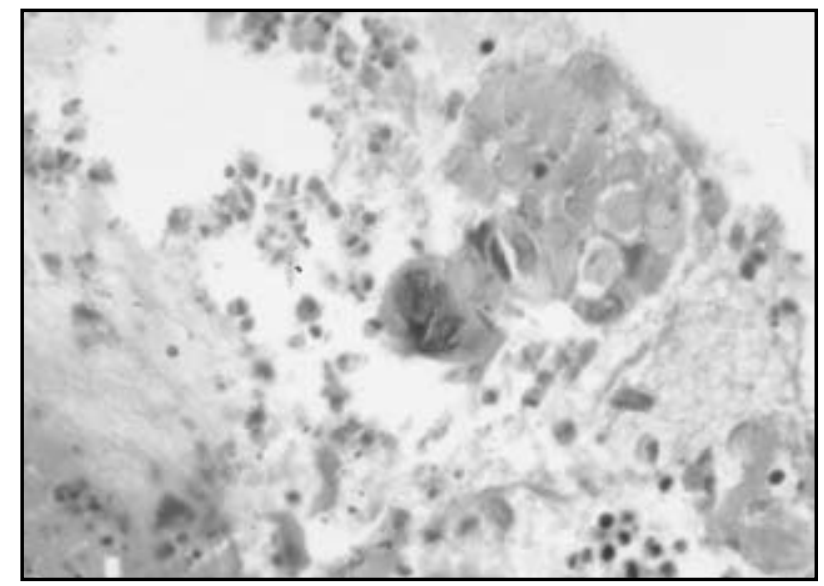

Figura 3 - Células de núcleos irregulares, cromatina de aspecto lavado, algumas células multinucleadas com amoldamento nuclear (H\&E 100x)

no mesmo local ou em região próxima. Essas recidivas podem ser induzidas por vários estímulos, tais como trauma, radiação ultravioleta, extremos de temperatura, estresse ou imunossupressão(9).

A primoinfecção acomete geralmente crianças, levando a um quadro de gengivoestomatite e odinofagia. Há presença de lesões vesicoerosivas, febre e adenopatia com ou sem comprometimento do estado geral. A duração é de, aproximadamente, duas a seis semanas. A recidiva é mais comum nos adultos, podendo ocorrer em qualquer área do corpo; entretanto, aparecem mais freqüentemente nos lábios ${ }^{(12)}$. Há pródromo de ardência e dor, as vesículas surgem agrupadas, evoluindo para pústulas e posterior exulceração e formação de crosta. Geralmente, o diagnóstico baseia-se no quadro clínico, que costuma ser característico ${ }^{(1)}$.

As lesões cutâneas do herpes surgem freqüentemente pela imunossupressão, em pênfigos, micose fungóide e 
outros linfomas, leucemia, mieloma, transplantes, doenças crônicas e $\operatorname{AIDS}^{(6,17)}$. Nesses casos, as lesões são mais extensas e podem ocorrer úlceras necróticas.

O reconhecimento da infecção cutânea pelo herpes simples vírus em pacientes imunodeprimidos pode ser difícil em virtude de sua apresentação atípica ${ }^{(19)}$. As lesões podem se manifestar como ulcerações grandes, crônicas ou hiperceratósicas, podendo não haver história prévia de surgimento de vesículas ${ }^{(17)}$. Em alguns pacientes, as lesões podem ser discretas e assintomáticas. Essas apresentações atípicas podem dificultar o estabelecimento do diagnóstico e, conseqüentemente, levar ao atraso do tratamento. Nesses indivíduos, a possibilidade de infecção por herpes deve ser considerada sempre que houver a presença de úlceras crônicas da pele e quando estas tardarem a cicatrizar.

Muitas vezes são necessários estudos complementares para que se possa firmar o diagnóstico. Um método eficaz é a citodiagnose de Tzanck, através do qual encontram-se células gigantes multinucleadas ${ }^{(12)}$. Entre outros procedimentos estão a cultura, a sorologia ${ }^{(16)}$ e o exame histopatológico. A biópsia da pele afetada pode ser de grande auxílio no diagnóstico. As principais alterações histopatológicas das infecções por herpes vírus mostram a presença de células gigantes acantolíticas multinucleadas. Nas fases iniciais há palidez e edema dos ceratinócitos, com nucléolo condensado perifericamente, acantose, vesículas intra-epidérmicas e corpos de inclusão intranuclear. $O$ diagnóstico se torna mais difícil nas fases mais avançadas da doença, pois as células epiteliais alteradas podem ser sutis ou estarem presentes em focos localizados nos anexos cutâneos ${ }^{(10)}$.
A maioria das infecções por HSV são autolimitadas. Entretanto, a terapia antiviral encurta o curso da infecção e pode prevenir a disseminação e a transmissão. $O$ tratamento via oral é efetivo, e podem ser utilizados o aciclovir, o valaciclovir e o famciclovir. O primeiro, na dose de $200 \mathrm{mg}$, cinco vezes ao dia, por cinco dias, tem apresentado resultados favoráveis. Em imunossuprimidos, a dose pode ser duplicada de acordo com o critério médico ${ }^{(15)}$. Para pacientes muito debilitados, o tratamento pode ser feito por via endovenosa, com uma dose de $5 \mathrm{mg} / \mathrm{kg}$ de aciclovir por sete dias ${ }^{(8)}$. O tratamento tópico, usualmente não-efetivo na doença que ocorre nos indivíduos hígidos, também foi aprovado pela Food and Drug Administration (FDA) para uso em lesões recorrentes, somente nos pacientes imunossuprimidos ${ }^{(18)}$. Naqueles que recebem quimioterapia, a vidarabina mostrou ser eficaz, podendo ser usada como profilaxia previamente ao transplante de medula óssea ${ }^{(13)}$.

Nos casos em que há resistência ao aciclovir, recomenda-se o uso do foscarnet via parenteral( ${ }^{(5)}$. Outras alternativas incluem vidarabina ${ }^{(3)}$, fludarabina ${ }^{(2)}$, cidofovir ${ }^{(7)}$, trifluorotimidina $^{(14)}$, interferon-alfa e SP-303 ${ }^{(11)}$.

\section{Conclusão}

Doenças comuns da pele podem ter apresentação atípica em pacientes imunossuprimidos ${ }^{(9)}$. Na infecção pelo HSV, pode incluir formas vegetantes em locais atípicos, casos moderados e até assintomáticos ${ }^{(4)}$. Pelas características diversas, o diagnóstico torna-se difícil, e até mesmo a presença de cultura negativa para HSV não o exclui. Portanto, o profissional médico deve sempre estar atento a lesões orofaciais e perineais, e o diagnóstico de infecção por HSV deve ser sempre considerado.

\section{Referências}

I. ALCHORNE, M. M. A.; ALCHORNE, A. O. A. Infecções cutâneas virais. In: CUCÉ, L. C.; FESTA NETO, C. Manual de dermatologia. 2 ed. São Paulo: Atheneu, 2001. p. 208-9.

2.ANAISSIE, E. J. et al. Infections in patients with chronic lymphocytic leukemia treated with fludarabine. Ann Intern Med, v. 129 , n. 7, p. 559-66, 1998.

3. FIELD, A.; BIRON, K. "The end of innoncence" revised: resistence of herpesviruses to antiviral drugs. Clin Microbiol Rev, v. 7 , p. 1-13, 1994.

4. GROSS, G.; DOERR, H.W. Atypical herpes simplex virus type 2 manifestations on the hand. Hautarzt, v. 52, n. 9, p. 809 $9 \mid 1,2001$
5. HARDY,W. Foscanet treatment of acyclovir-resistant herpes simplex virus infection in patients with acquired immunodeficiency syndrome: preliminary results of a controlled, randomized, regimen-comparative trial. Am J Med, v. 92, p. S30-S35, 1992.

6. HIRSCH, M. S. Herpes group virus infectious in the compromised host. In: RUBIN, R. H.; YOUNG, L. S. Clinical approach to infection in the compromised host. 3 ed. New York: Plenum, 1994. p. 380.

7. LALEZARI, J. et al.A randomized, double-blind, placebo-controlled trial of cidofovir gel for the treatment of acyclovirunresponsive mucocutaneous herpes simplex virus infection in patients with aids. J Infect Dis, v. 176, p. 892-8, 1997. 
8. MEYERS, J. D. et al. Multicenter collaborative trial of intravenous acyclovir for treatment of mucocutaneous herpes simplex virus infection in the immunocompromised host. Am J Med, v. 73, suppl IA, p. 229-35, 1982.

9. MINDEL, A. Cutaneous herpes simplex infection. Scand J Infect Dis, v. 78, p. 47-52, 1991.

10. RESNIK, K. S.; DILEONARDO, M. M. Herpes Incognito. Am J Dermatopathol, v. 22, n. 2, p. 144-50, 2000.

I I. SAFRIN, S. et al. Treatment of acyclovir-unresponsive cutaneous herpes simplex virus infection with topically applied SP-303. Antiviral Res, v. 25, p. 185-92, 1994.

12. SAMPAIO, S.A. P.; CASTRO, R. M.; RIVITTI, E.A. Dermatoviroses. In: SAMPAIO, S. A. P.; CASTRO, R. M.; RIVITTI, E. A. Dermatologia básica. 2 ed. São Paulo: Artes Médicas, 200 I. p. 409 - 13.

13. SARAL, R.; BURNS, W.; PRENTICE, H. Herpes virus infections: clinical manifestations and therapeutic strategies in immunocompromised patients. Clin Haematol, v. 149, p. I-8, 1984

14. SNOECK, R. et al. Successful treatment of progressive mucocutaneous infection due to acyclovir and foscarnetresistant herpes simplex virus with (S)- I-(3-hydroxy-2phosphonylmethoxypropyl) cytosine (HPMCP). Clin Infec Dis, v. I8, p. 570-8, 1994.

15. STRAUS, S.; SMITH, H.; BRICKMAN, C. Acyclovir for chronic mucocutaneous herpes simplex virus infection in immunosuppressed patients. Ann Intern Med, v. 96, p. 270-7, 1982.

16. Tebache, E. S. et al. Detección del virus herpes simple en lesiones de la mucosa oral en pacientes con terapia oncológica. Med Oral, v. 8, p. 329-833, 2003.

17. VONDERHEID, E. C. et al. Chronic herpes simplex infection in cutaneous T-cell lymphomas. Arch Dermatol, v. I 16, p. $1018-22,1980$.

18. WHITLEY, R. et al. Infections caused by HSV in the immunocompromised host: natural history and topical ACV therapy.J Infect Dis, v. 150, p. 323-9, 1984.

19. WRIGHT, S. W.; JOHNSON, R. A. Human Immunodeficiency virus in women. Clin Dermatol, v. 15, n. I, p. 93-1। I, 1997. 